\title{
Comparison of WC-10Co-4Cr coatings properties produced by HVOF and HVOLF processes for application in petrochemical industry
}

\author{
Anas Mahmoud Atieh \\ Department of Industrial Engineering \\ German Jordanian University \\ Amman, Jordan \\ Anas.atieh@gju.edu.jo
}

\author{
Abdulaziz AlHazaa \\ Physics \& Astronomy Department \\ King Saud University \\ Riyadh, KSA
}

\author{
Rohit Upadhyaya \\ Research and Development Department \\ Metallizing Equipment Co. Pvt. Ltd \\ Jodhpur, India
}

\begin{abstract}
This research work presents the results of a comparative study conducted to compare the coatings properties of WC-10Co-4Cr coats produced by two different Oxy-fuel coating process; high velocity oxy-gas fuel (HVOF) and high velocity oxy-liquid fuel (HVOLF) thermal spraying techniques. The coats were deposited directly on low carbon steel substrate without bonding coats. Scanning electron microscopy (SEM) was performed to study microstructural analysis and to quantify the porosity and cross-sectional coat thickness. Furthermore, the mechanical properties of both coating processes were defined in terms of bond strength and micro hardness. The results show that the liquid fuel sprayed coatings (HVOLF) produced higher adhesion strength coats $(\sim$ $73 \mathrm{MPa}$ ) compared to ( $68 \mathrm{MPa})$ for HVOF. Similar results observed for micro-hardness of $1255 \mathrm{VHN}$ and $1032 \mathrm{VHN}$, respectively. The surface roughness and porosity were less for HVOLF $4.32 \mu \mathrm{m} / 0.85 \%$ compared to HVOF results of $5.26 \mu \mathrm{m} / 1.29 \%$ porosity. This superior result in coats properties of HVOLF compared to HVOF was attributed due to less decarburization in HVOLF and hence less production of hard secondary phases of $\mathrm{W}_{2} \mathrm{C}$.
\end{abstract}

Keywords-component; HVOF; HVOLF, WC-10Co-4Cr; Coating properties

\section{INTRODUCTION}

Engineering components in service under sever operational conditions i.e. erosive, corrosive and wear requires continuous maintenance using coated alloy materials $[1,2]$.
Thermal spraying techniques such as HVOF and HVOLF can be utilized to produce a variety of wear/erosion resistance coatings onto a wide range of substrate material with numerous possibility of coating powders [3]. Semi-molten material state is deposited onto the substrate through the acceleration of powder particles to high velocity through the coating nozzle while physical interlocking occurred at substrate surface and splat deformation occurred due to high kinetic energy hence the process produces dense coat with superior wear and corrosion resistance [3-7].

Ceremet coating of WC-CoCr composed of hard WC phase and relatively softer $\mathrm{Co}$ and $\mathrm{Cr}$ have been developed and studied extensively by many researchers [8] and resulted in dense, good toughness and high corrosive resistance coatings $[9,10]$.

In this paper, the effect of fuel type either gaseous (propane) in HVOF compared to liquids aviation turbine fuel (ATF) in HVOLF is studied on the produced coats in terms of hardness, adhesion strength, porosity, thickness and microstructure.

\section{MethodOLOGY}

Commercial feedstock powder of WC-10Co-4Cr was sprayed by two techniques HVOF and HVOLF, Fig.1 shows the SEM micrograph of feedstock powder. As shown in the figure the shape and morphology of the powder particles are not uniformed for the WC-10Co-4Cr powder. 


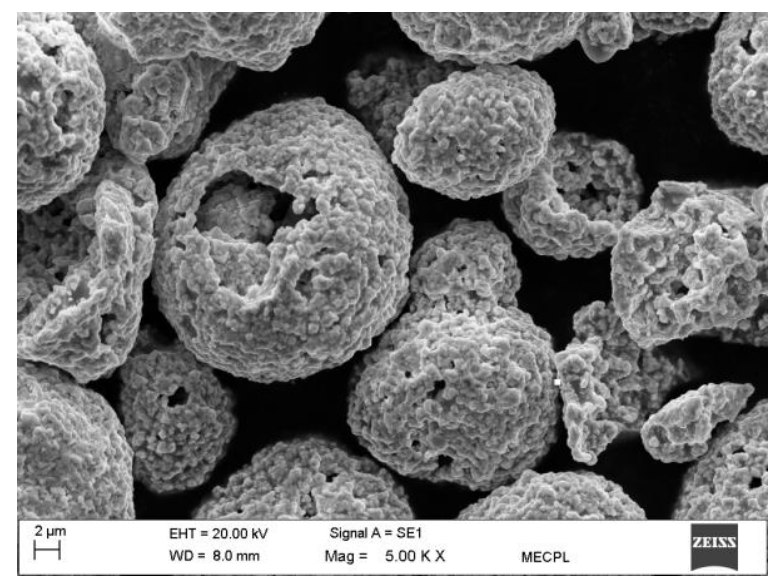

\section{Figure 1. SEM micrograph of WC-10Co-4Cr feedstock powder}

The grain size of the powder was measured as $15-45 \mu \mathrm{m}$ of agglomerated grains. Round specimen of $30 \mathrm{~mm}$ diameter and $10 \mathrm{~mm}$ high were prepared by blasting with alumina powder $\left(\mathrm{Al}_{2} \mathrm{O}_{3}\right)$ and air blown for cleaning. The HVOF and HVOLF spraying process was carried out at the laboratories of Metallizing Equipment Company Pvt. Ltd. a Nobal accredited laboratory (CERT. No. T-3514). Adhesion test was carried out at universal testing machine UTM Instron USA - Model 5969 (50 kN Capacity) according to ASTM C-633:2013 standards. A Shimadzu HVM-G Vickers micro-hardness tester was used to measure micro hardness according to ASTM E384-2011 where five measurements are taken for each sample with test force of HV0.3 and 8 seconds dwell time. Carl-Ziess (UK) scanning electron microscopy (SEM) model EVO-18 was utilized to measure porosity as per ASTM E-2109:2007 standards cross sectional thickness as per EN ISO 1463:2003 standards, and for microstructural analysis.

\section{RESULTS AND DISCUSSION}

\section{A. Microstructural and surface analysis}

The microstructure of the coatings were examined using the SEM, and the micrographs of the WC-10Co-4Cr HVOF and HVOLF are shown in Fig. 2 a \& b, respectively.

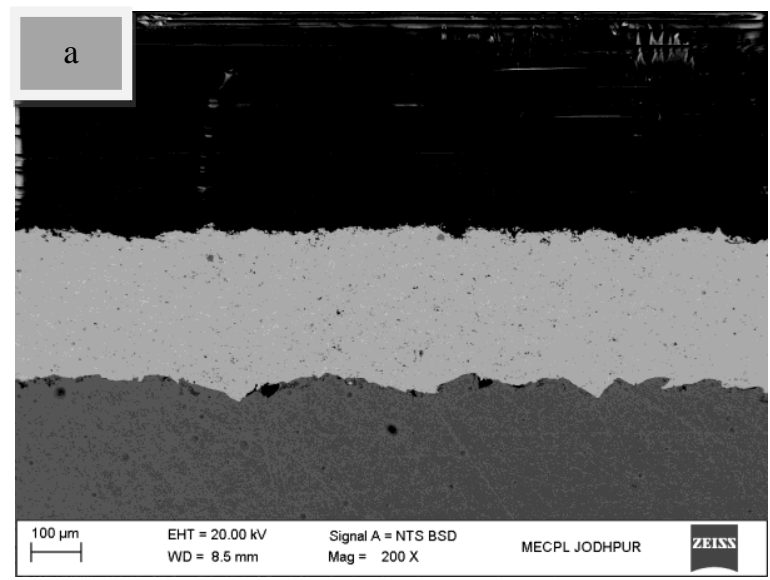

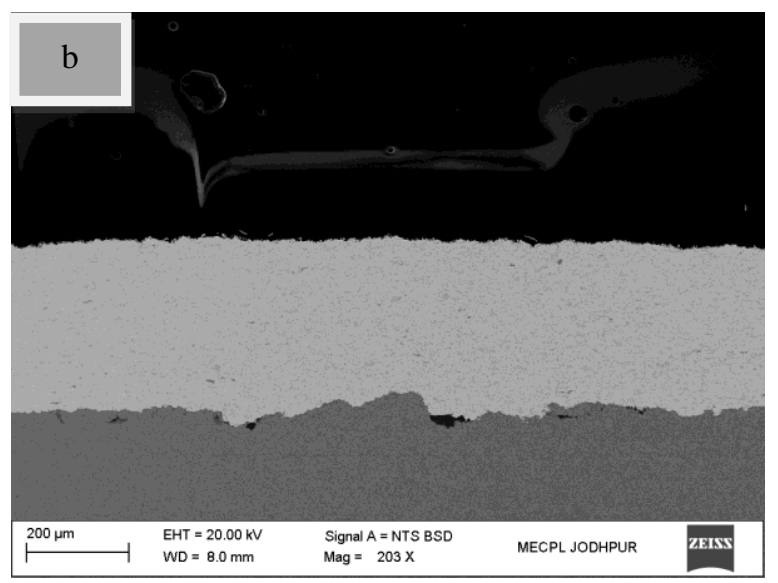

Figure 2. SEM micrograph for WC-10Co-4Cr (a) HVOF and (b) HVOLF sprayed coating

It can be seen that the coatings produced by both processes HVOF and HVOLF resulted in a homogenous coats. The microstructural analysis showed that HVOF coating contained higher percentage porosity of $1.29 \%$ at a total magnification of $200 X$ compared to $0.85 \%$ for HVOLF coating under same total magnification.

Furthermore, the produced coating thickness were higher for HVOLF coatings compared to HVOF under same spraying conditions for both processes. The Fig. 3 below shows the average coating thickness measured on a diagonal of the cross section for both samples.

The surface roughness of the as sprayed coatings ( $\mathrm{Ra}$ ) were lower for HVOLF compared to HVOF, which indicates smoother surface finish produced by HVOLF, Fig. 4 shows the average surface finish for both processes in the as sprayed condition.

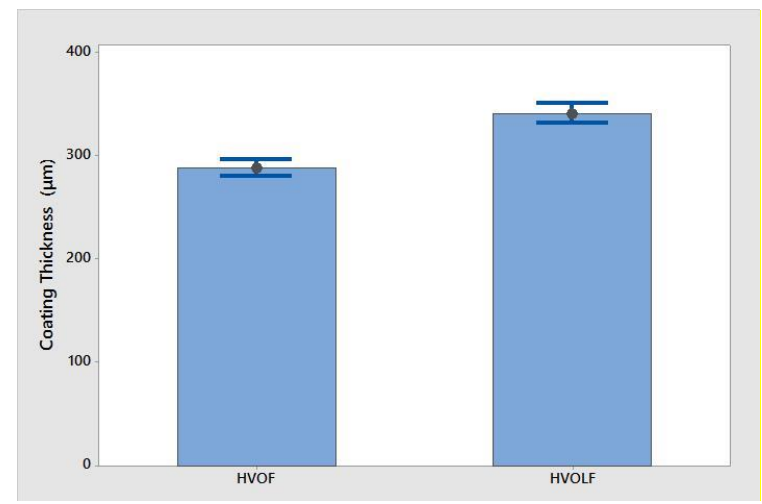

Figure 3. Average coat thickness measured on the cross section for HVOF and HVOLF 


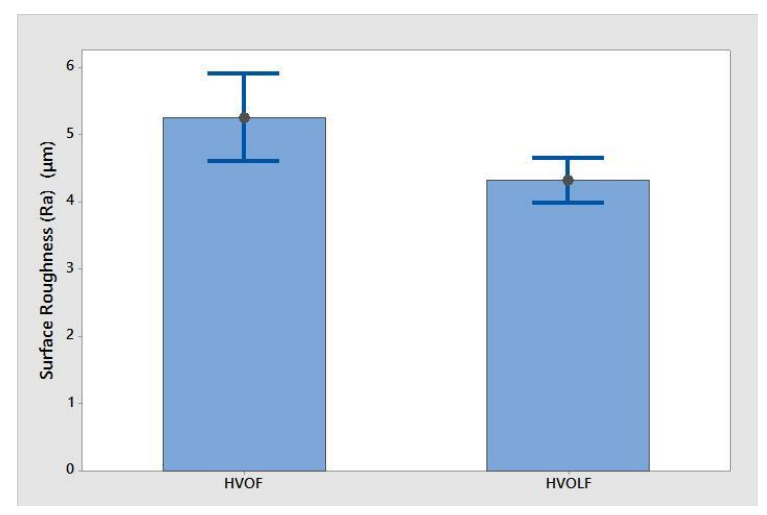

Figure 4. Average surface roughness measured for HVOF and HVOLF

\section{B. Microhardness measurments}

The average microhardness value for the HVOF was 1032 VHN and a higher average hardness value of $1255 \mathrm{VHN}$ was obtained for the HVOLF process. The coatings in both processes showed a uniform hardness profile by the five hardness measurements taken at different locations at the coatings through the entire thickness of the coatings confirming the homogeneity of the produced coatings.

\section{Table 1. Microhardness measurements at coatings} produced by HVOF and HVOLF

\begin{tabular}{|l|c|c|c|c|c|}
\hline & $\mathbf{1}$ & $\mathbf{2}$ & $\mathbf{3}$ & $\mathbf{4}$ & $\mathbf{5}$ \\
\hline HVOF & 955 & 1026 & 989 & 1087 & 1102 \\
\hline HVOLF & 1286 & 1324 & 1166 & 1206 & 1292 \\
\hline
\end{tabular}

The higher coating density in HVOLF using the liquid fuel can explain this increase in microhardness.

\section{Adhesion strength}

The strength tests were performed in order to compare the bondability and adhesion of the coatings to substrate. In both HVOF and HVOLF a failure in glue were observed, Fig. 5 shows the bond strength results of both coatings in MPa.

In thermal spray, processing of WC a decarburization occurs during the spraying producing reaction products $\mathrm{W}_{2} \mathrm{C}$, $\mathrm{W}$ and $\mathrm{C}$. It was reported by Saha et al. that $\mathrm{W}$ and $\mathrm{C}$ may dissolve in the Co matrix and promote the formation of amorphous Co matrix [11]. In the current research work, it is expected that less decarburization occurred in case of HVOLF. Less formation of hard phases $\mathrm{W}_{2} \mathrm{C}$ may explain the higher bond strength of HVOLF compared to $\mathrm{HVOF}$ as $\mathrm{W}_{2} \mathrm{C}$ may work as a stress raiser within the coating matrix and resulted in coat failure.

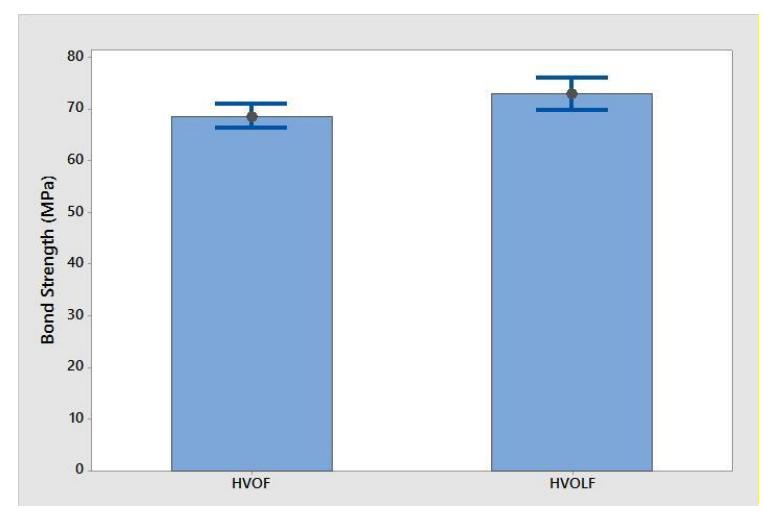

Figure 5. Average bond strength for HVOF and HVOLF

\section{CONCLUSIONS}

In this study, two thermal spraying processes of HVOF and HVOLF deposited WC-10Co-4Cr successfully. The results showed that liquid fuel process (HVOLF) sprayed coatings have less porosity ( $0.85 \%$ compared to $1.29 \%$ in HVOF), higher coating thickness $(341 \mu \mathrm{m}$ compared to $288 \mu \mathrm{m})$, higher microhardness of $1255 \mathrm{VHN}$, and higher bond strength with 73 $\mathrm{MPa}$ in HVOLF compared to $68 \mathrm{MPa}$ in HVOF).

The increase in the mechanical properties of the coatings and therefore the performance was attributed to the formation of less hard phases due to less decarburization effect of WC and formation of amorphous Co matrix.

\section{ACKNOWLEDGMENT}

The authors gratefully acknowledge the financial support provided by German Jordanian University, Grant number SATS 12/2015. Samples preparations and characterization as provided by Metallizing Equipment Co. Pvt. Ltd (MEC) Jodhpur, India are also acknowledged.

\section{REFERENCES}

Spadlo, S., Depczynski, W., and Mlynarczyk, P., 2017, "Selected Properties Of High Velocity Oxy Liquid Fuel (HVOLF) - Sprayed Nanocrystalline WCCo Infralloytm S7412 Coatings Modified By High Energy Electric Pulse," METALURGIJA, 56(3-4), pp. 412-414.

[2] Davies J.R., 2004, Handbook of Thermal Spray Technology, ASM International.

[3] Peat, T., Galloway, A., Toumpis, A., Harvey, D., and Yang, W. H., 2016, "Performance Evaluation of HVOF Deposited Cermet Coatings under Dry and 
Slurry Erosion," Surf. Coatings Technol., 300, pp. 118-127.

[4] Ben Mahmud, T. A., Atieh, A. M., and Khan, T. I., 2017, "The Wear Behavior of HVOF Sprayed NearNanostructured WC-17\%Ni(80/20)Cr Coatings in Dry and Slurry Wear Conditions," J. Mater. Eng. Perform., 26(7), pp. 3507-3515.

[5] Bolelli, G., Lusvarghi, L., and Barletta, M., 2009, "HVOF-Sprayed WC-CoCr Coatings on Al Alloy: Effect of the Coating Thickness on the Tribological Properties," wear, 267, pp. 944-953.

[6] García, J. R., Fernández, J. E., Cuetos, J. M., and Costales, F. G., 2011, "Fatigue Effect of WC Coatings Thermal Sprayed by HVOF and Laser Treated, on Medium Carbon Steel," Eng. Fail. Anal., 18, pp. 1750-1760.

[7] J.G. La Barbera-Sosa, Y.Y. Santana, C. VillalobosGutiérrez, D. Chicot, J. Lesage, X. Decoopman, et al, 2013, "Fatigue Behavior of a Structural Steel Coated with a WC-10Co- 4Cr/Colmonoy 88 Deposit by HVOF Thermal Spraying," Surf. coatings Technol., 220, pp. 248-256.

[8] Karaoglanli, A. C., Caliskan, H., Oge, M., Doleker, K. M., and Hotamis, M., 2017, "Comparison of Tribological Properties of HVOF Sprayed Coatings with Different Composition," Surf. Coatings Technol., 318, pp. 299-308.

[9] Thakur, L., Arora, N., Jayaganthan, R., and Sood, R., 2011, "An Investigation on Erosion Behavior of HVOF Sprayed WC-CoCr Coatings," Appl. Surf. Sci., 258(3), pp. 1225-1234.

[10] Barletta, M., Bolelli, G., Bonferroni, B., and Lusvarghi, L., 2010, "Wear and Corrosion Behavior of HVOF-Sprayed WC-CoCr Coatings on Al Alloys," J. Therm. Spray Technol., 19(1-2), pp. 358-367.

[11] Saha, G. C., Khan, T. I., and Glenesk, L. B., 2008, "Development of Wear Resistant Nanostructured Duplex Coatings by High Velocity Oxy-Fuel Process for Use in Oil Sands Industry," J. Nanosci. Nanotechnol., 8(1-8). 